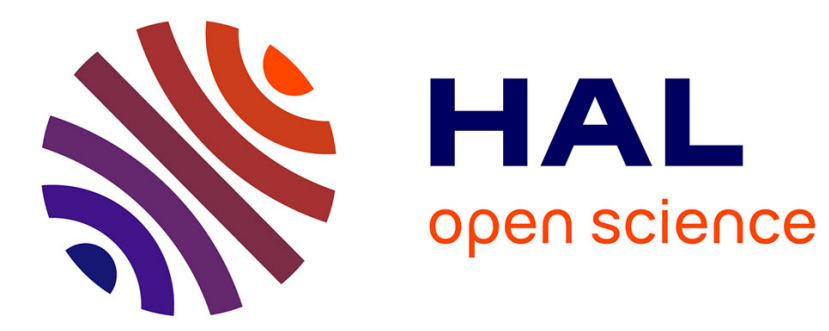

\title{
Gamification and Family Housework Applications
}

Anne Bjering, Marikken Høiseth, Ole Andreas Alsos

\section{To cite this version:}

Anne Bjering, Marikken Høiseth, Ole Andreas Alsos. Gamification and Family Housework Applications. 14th International Conference on Entertainment Computing (ICEC), Sep 2015, Trondheim, Norway. pp.209-223, 10.1007/978-3-319-24589-8_16 . hal-01758462

\section{HAL Id: hal-01758462 \\ https://hal.inria.fr/hal-01758462}

Submitted on 4 Apr 2018

HAL is a multi-disciplinary open access archive for the deposit and dissemination of scientific research documents, whether they are published or not. The documents may come from teaching and research institutions in France or abroad, or from public or private research centers.
L'archive ouverte pluridisciplinaire HAL, est destinée au dépôt et à la diffusion de documents scientifiques de niveau recherche, publiés ou non, émanant des établissements d'enseignement et de recherche français ou étrangers, des laboratoires publics ou privés.

\section{(c)(1)}

Distributed under a Creative Commons Attribution| 4.0 International License 


\title{
Gamification and Family Housework Applications
}

\author{
Anne Berit Kigen Bjering ${ }^{1}$, Marikken Høiseth ${ }^{1}$, Ole Andreas Alsos ${ }^{2}$ \\ Norwegian University of Science and Technology (NTNU), \\ ${ }^{1}$ Department of Product Design, Kolbjørn Hejes vei 2B, \\ ${ }^{2}$ Department of Computer and Information Science, Sem Sælands vei 9, \\ 7491 Trondheim, Norway \\ ab.bjering@gmail.com
}

\begin{abstract}
This conceptual work represents an initial exploration into a little researched area, namely app design for families. We explore how gamification is incorporated in applications that target family housework, also known as chores. During the last five years an increasing number of apps aim to transform routine based housework into entertaining activities. Many parents think it is important that children, at an early age, learn about family values and responsibilities that comes with the role as a family member. However, a gamified approach towards housework can influence family interaction in both positive and negative ways. We analyze a selection of so-called chore apps by building on an existing classification framework for educational apps and applying concepts of game design elements. Our findings show (1) that existing apps tend to be mostly instructive and partly manipulable, (2) that they tend to focus on external rather than intrinsic motivation, (3) that they target family members individually, rather than the family as a whole. We discuss the results from a motivation perspective by drawing attention to three concepts that relate to intrinsic motivation: Competence, autonomy and relatedness.
\end{abstract}

Keywords: Gamification, housework, family, motivation, children, parents

\section{Introduction}

This paper is connected to an ongoing project that aims at developing a system to motivate children between 6 and 12 years to contribute with housework. The idea is based on own experience and observations of parents wanting children to participate at home, but struggling to engage and motivate them. Housework refers to tasks such as cleaning the house, doing laundry, preparing meals and doing the dishes. The system is intended to address children, but it should be relevant for the whole family.

The purpose of this paper is to shed light on the topic of gamification in apps targeting family housework by drawing on concepts from motivation theories. Deterding et al. [1, p.9] define gamification as "the use of game design elements and game thinking in a non-gaming context". Doing housework can typically be considered a non-game context. Building on the idea of gamification, a recent trend in apps is to target housework aiming to transform boring chores into entertaining activities. This gamified approach towards housework seems especially relevant for 
families with children in elementary school age, but also for preschool-aged children. One reason for this is that many parents want their children to learn about responsibilities that come with the role as a family member. Another reason is that many children, along with parents, use applications on a daily basis for playing, learning and sustaining social interaction. Thus, the recognition that both housework and games are strongly present in many modern families has led to development of apps that seek to combine the two.

Our point of reference is a Scandinavian context. Here, gender equality policies are based on the idea that "women and men should have the same opportunities, rights and responsibilities in all significant areas of life...This includes shared responsibility for work in the home and with children" [2]. However, research about younger couples in the Nordic countries shows that "daily life practice often differed from their ideals" and that families in these countries "report more disagreement about the division of housework" compared to "countries with more traditional gender regimes" [3].

Taking this as a starting point, the paper is structured as follows: Section 2 introduces different approaches that families use to organize their housework. Section 3 presents some key concepts from motivation theory and gamification. Section 4 describes the research method. Section 5 presents the results, in 3 position axes. In section 6 we discuss the results. Finally, section 7 offers concluding remarks and suggestions for future research. Through this conceptual work, we aim to inspire and challenge game developers to create better apps for families.

\section{Approaches to Organize Family Housework}

There is a large amount of literature in sociology and related disciplines that provide interesting perspectives on how families organize and negotiate housework. For instance, Solberg [4] views childhood as a social construction, understanding conceptions about childhood to be part of culture that transforms in time and space, end explores children's roles in Norwegian family housework contexts. Informed by gender and welfare state theories, a lot of research investigates relations between national practices and policies and how women and men spend their time on housework [2], [5]. Research shows that men have a greater share of housework in Scandinavian countries, where women's economical and political power is greater, and in nations where divorce culture is strong [2]. Taking a social learning perspective, researchers demonstrate how attitudes about gender and housework are shaped in early childhood and that parental practices strongly influence children's own future expectations and attitudes about housework distribution [2], [6].

Families use different strategies to encourage children's contributions to housework. Bjering [7] used a combination of questionnaires, observations and home interviews with the whole family to investigate how Norwegian families organized their family life and chores. As explained in the following, a wide variation was found:

Verbal instructions and demonstrations: Parents include children in housework by show and tell; they use verbal instructions and demonstrations to motivate the children and to make clear what their tasks are and how to perform them. 
Books: Some parents use books which thematize housework [8, 9]. These books attempt in a pedagogical way, often through a character, to bring attention to the benefits of helping at home and how to do it. Our literature search showed that most of these books are for children aged 2-5 years.

Calendars, boards and checklists: Several of the parents used homemade solutions to motivate children to help with chores. Many of these took form as boards with checklists, task lists or calendars where the children get a sticker or a magnet for every finished chore. Some of these are also available as products on the market.

Digital tools: Parents had three main attitudes towards digital tools to help with chores. A few parents already used digital tools (usually checklists) to help get an overview of the chores. Another group of parents did not use digital tools for this, but wanted to try it. The last group of parents was negative towards digital tools for tracking chores.

Rewards: Most of the parents stated that they praised their children after they have finished a chore. In addition, parents usually follow one of the following reward strategies: 1) to see chores as everyone's responsibility and therefore non-paid work, or 2) to pay the children for each chore they do, or 3) to pay a weekly or monthly allowance when the child completes the agreed set of chores (some parents deducted an amount from the allowance if the child failed to complete the agreed chores).

\section{Theoretical Background}

\subsection{Motivation and Reward}

Many theories exist on motivation, and different perspectives have led to a great variety. Motivation is the direction of behavior and its energy, originally meaning "to be moved" to something" [10]. Taking it further, one can say that there must be an interaction between a person and a task, for the person to be motivated. The orientation of the motivation answers why we want to move or act; namely the reasons or goals. Throughout the years two major fields have gained more interest than others: behaviorism and social cognitive theory [11].

Behaviorism is based on the theory that people are motivated only because of external responses to stimuli. The best known psychologists in this field are Ivan Pavlov and B. F. Skinner, both of them doing motivation research on animals such as rats [12]. They saw that the animals reacted in predictable ways to rewards and punishment, and extrapolated the results onto the human being. In short, they saw extrinsic motivation as the best way to encourage people to do activities.

Social cognitive theorists were skeptical to parts of Skinner's work, mostly because his approach assumes that people are "industrial machines", and not social human beings with the capability of thinking [13]. Edward Deci and Richard Ryan are two influential psychologists in this field, with their theory of Self-determination (SDT). SDT says that people have inherently a strong internal desire for growth, but that the surroundings must support this; if they do not, the internal desire might die [14].

Social cognitive theory focuses on people's desire to flourish and to do what makes them happy. Whereas intrinsic motivation is about our willingness to do a task for the enjoyment or interest of the task itself, extrinsic motivation refers to a separable 
outcome or consequence [15]. Intrinsic motivation as explained by Deci and Ryan, correlates well with Csikszentmihalyis concept of flow: whatever produces flow becomes its own reward [16]. To be in flow one must have equally high skills and challenges.

Deci and Ryan also point out that rewards might have negative effects if they are poorly implemented. The reward might actually decrease the interest for an activity, and cause people to choose the least challenging task, because it is the safest way to a reward. By doing so, people do not get in flow, and the intrinsic motivation is lost. According to SDT, intrinsic motivation and human needs consist of three major elements: competence, autonomy and relatedness [14].

Some motivational theories are especially adapted to the work setting [17]. In some ways one can say that doing household chores is a part-time job. It is therefore interesting to look at some work motivation theories as well. Hackman and Oldham's job characteristic model [18] is based on the principle that employees derive motivation from completing a task, and it builds upon SDT. The following three psychological states relate to motivation: 1) The task must be meaningful, 2) The task must give you responsibility, so that you can plan and do the task the way you think is best and 3) You need feedback - how effective have you been, when doing the task?

Especially when doing chores, we should acknowledge that some jobs are actually quite boring - e.g. to clean the toilet. According to this model, we should find ways to provide meaning. This means that one has to show importance of the work, and how the effort affects other people in the organization, or the family in our case. Herzberg's motivation and hygiene theory distinguishes between two factors: those that genuinely motivate staff, and those that can provide small amounts of dissatisfaction if they fall below acceptable levels [19]. Examples on the latter, called hygiene factors, are pay, working conditions and relationship with supervisors. Examples of motivating factors are achievement, responsibility, recognition and the nature of the work (how exciting it is by itself). The recommendation is to set realistic, but challenging tasks and recognize and celebrate achievements publicly. Moreover, autonomy is important in this theory as well.

Should we think differently when trying to motivate children? Focusing on children's motivation, Bandura's theory about self-efficacy and Covington's selfworth theory are considered central [20]. Self-efficacy refers to how people judge their own operative capabilities, thus what they think they are able to do with their skills under certain circumstances [21]. Self-worth refers to the value that people places on their own perceived abilities, qualities, and attributes [22].

Why should children have chores while growing up? As members of a family, children's responsibility for selected and meaningful tasks can benefit their sense of self-efficacy and self-worth on the home arena. Under the right conditions, taking part in the house chores can foster competence, autonomy and relatedness in both children and parents. Toddlers see success as a result of effort; high effort enhances the chance of mastering a task. When the children get older, their expectation about success is more attached to skills or capabilities, and less to effort [20]. This means that they start comparing themselves to others. Covington underlines that children's perception of their own skills is a major part of their self-perception, and has therefore an impact on the self-esteem and motivation [22]. 
In different situations people can respond differently to activities, and either be demotivated (do not care), intrinsically motivated (want to do it for the genuine pleasure) or extrinsically motivated (want to do the activity to get something in addition to the task). Regarding children's motivation to contribute with housework how can we pull the right triggers so that the environment will facilitate intrinsic motivation? This is where gamification can play a role. Children, like adults, use applications on a daily basis to play, learn and sustain social interaction. Research about children's internet use in European countries shows that children access the internet at younger and younger ages; many preschoolers are already experienced game players [23].

\subsection{Gamification}

The field of "Gamification" has the past years gained significant interest and the actual term can be explained as the application of game design elements and game mechanics, in none-game contexts [1]. Gamification can be used to create engagement, solve problems, change behavior or create better experiences [24]. It has been used mainly in the software industry, but now fields such as marketing, tourism, health and education see a potential for including game elements in their services and businesses [25].

Gamification builds upon the elements and design of games, but it does not constitute a game in itself. To better understand how gamification works, we take a look at games. What are games, and what makes games fun? What motivates us to play? The Danish videogame researcher Jesper Juul defines games with six elements [26]: 1) There is a set of rules, 2) A variable and quantifiable outcome, 3) Different outcomes are assigned different values (e.g. positive and negative), 4) Interactive: The players can influence the outcome by doing some effort, 5) The players are emotionally attached to the outcome, 6) Negotiable consequences: The game can be played with or without real-life consequences. Only when all of these criteria are present, we have a game.

Other ways to define a game include elements as players, conflict, competition and collaboration, rules, feedback systems, quantifiable outcomes and voluntary participation [27, 28] and self-representation with avatars, narrative context, time pressure, reputations/ranks/levels and teams [29].

The core of gamification is to apply a set of external motivation elements, which should facilitate intrinsic motivation - the desire to play along. Drawing on Deci and Ryan's SDT, Schell (2011) and Deterding (2011) point out the importance of the three aforementioned principles for gamification to achieve intrinsic motivation: 1) Competence: The feeling of mastering a system, by achieving clear and visual goals, 2) Autonomy: The freedom of choosing to participate or not, and not being controlled and 3) Relatedness: Interaction with other people, such as family and friends.

Gamification has also received quite some criticism. Schell outlines a gloomy scenario in which every activity in life becomes a game play - 10 points for brushing your teeth, 20 points for looking at advertisement, 30 points for eating the right cereal etc., and questions whether this is the kind of society that we really long for [30]. There has been lots of arguing about how we should apply game mechanics, and whether it serves its purpose or not. 
Recognizing that current debates on gamification are contested and not yet moving beyond superficial scoring systems, Cody Reimer draws attention to Johan Huizinga's work on play and his concept of the magic circle [31]. The magic circle is understood as the boundary of game play - as a "temporary world within the ordinary world" wherein the player experiences immersion and engagement [32]. As such, experiencing the magic circle aligns with experiencing intrinsic motivation and flow. Focusing on gamification in education, Reimer argues that because we can already understand education and life as a game, gamification should be understood as "a means to reveal the ways in which education or school is already a game" rather than considering gamification as a means to motivate students [31]. Applying these ideas thus means that we are challenged to shift the way we look at the non-game context. In our case, it encourages us to ask: How to reveal the ways in which housework is a game?

Game designer Margaret Robertson has a similar way of looking at the problem with gamification, or what she calls pointsification, and how it is being applied: "What we're currently terming gamification is in fact the process of taking the thing that is least essential to games and representing it as the core of the experience. Points and badges have no closer a relationship to games than they do to websites and fitness apps and loyalty cards. (...) They are the least important bit of a game, the bit that has the least to do with all of the rich cognitive, emotional and social drivers which gamifiers are intending to connect with" [33].

We agree with the criticism of the excessive use of points and reward systems. However, we adopt the claims holding that gamification, by moving beyond the superficial application of mere points, has the potential to foster immersion and engagement by considering the wide range of game design elements. This can be understood as a move from a behaviorist perspective to ideas upon which SDT builds (Constructivist paradigm).

\section{Method}

In this study we analyzed apps as the main method. The analysis was initially performed as a market/competition analysis. Therefore it lacks some of the scientific rigor that normally would have been applied. This part describes the way we performed the app search, app selection, and how we analyzed them.

To explore how gamification is incorporated in applications that target family housework, we searched for suitable apps from the main app providers, App Store, Google Play, and Windows Phone Store. We also searched through 12 forums (such as allparenting.com, bestappsforkids.com, and others), news sites, web magazines, as well as social media to get an overview of the most used and best rated apps. In this semi-structured Internet search we used the search terms chores, apps, motivate, house, family, game. The search was carried out in February and March 2015 and resulted in around 60 apps that aimed to motivate children to do specific tasks at home or to change their habits and behavior, or to help parents raise their children. We focused primarily on English-speaking apps.

Based on the number of positive and negative reviews, and whether they targeted children or children and parents, we selected 15 apps for further analysis. In this stage 
we did not consider standard to-do list apps, such as Wunderlist or Todoist, as they are targeting an adult audience. To limit the number of apps, we also discarded apps that were specifically targeting merely one kind of task such as cooking. We also limited the app selection to iOS apps.

All the apps were downloaded, installed and tested to get an overview of functionality, intended user groups, usability, etc. Based on this initial app testing we selected all 15 apps for further analysis (figure 1).

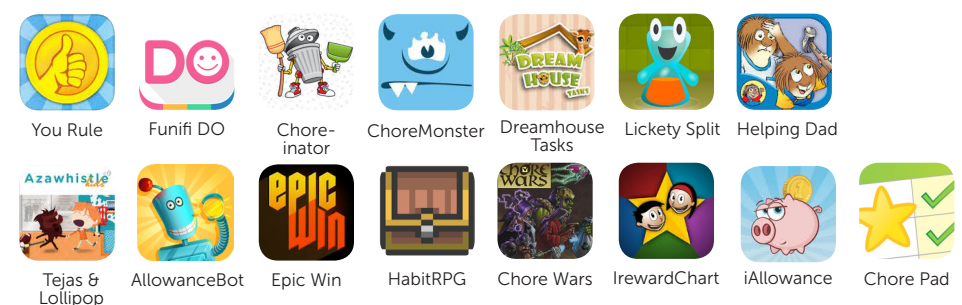

Figure 1: Selected apps

\begin{tabular}{|c|c|c|c|c|c|c|c|}
\hline Product & \multicolumn{2}{|c|}{ Description } & \multicolumn{2}{|l|}{ User } & Functionality & Motivation/Reward & Game elements \\
\hline $\begin{array}{l}\text { Name, } \\
\text { screenshots, } \\
\text { developer }\end{array}$ & \multicolumn{2}{|c|}{$\begin{array}{l}\text { The description } \\
\text { from the } \\
\text { producer or, } \\
\text { when missing, } \\
\text { the app home } \\
\text { page }\end{array}$} & \multicolumn{2}{|c|}{$\begin{array}{l}\text { Description } \\
\text { of the target } \\
\text { users and } \\
\text { their age }\end{array}$} & $\begin{array}{l}\text { Description } \\
\text { of the main } \\
\text { functionality }\end{array}$ & $\begin{array}{l}\text { Is the app based } \\
\text { on external (points, } \\
\text { badges or high } \\
\text { score list) or intrinsic } \\
\text { motivation? }\end{array}$ & $\begin{array}{l}\text { What kinds of game } \\
\text { elements or game } \\
\text { mechanics were } \\
\text { used in the app? }\end{array}$ \\
\hline \multicolumn{2}{|c|}{ Pedagogical Design } & \multicolumn{2}{|c|}{ User Interface } & \multicolumn{2}{|c|}{ Universal Design } & Technical Solution & Overall Impression \\
\hline \multicolumn{2}{|c|}{$\begin{array}{l}\text { Instructive, manipulable } \\
\text { or constructive } \\
\text { approach? }\end{array}$} & \multicolumn{2}{|c|}{$\begin{array}{l}\text { How is the } \\
\text { user interface } \\
\text { created? Is it } \\
\text { different for } \\
\text { children and } \\
\text { parents? }\end{array}$} & \multicolumn{2}{|c|}{$\begin{array}{l}\text { How is the app } \\
\text { using sound, text, } \\
\text { text size, images? } \\
\text { Is it relying on } \\
\text { text or images in } \\
\text { communication? }\end{array}$} & $\begin{array}{l}\text { Which technical } \\
\text { platform and } \\
\text { technology is used? } \\
\text { Does the app require } \\
\text { internet connection? }\end{array}$ & $\begin{array}{l}\text { An overall subjective } \\
\text { description of the } \\
\text { authors' impression of } \\
\text { the app. }\end{array}$ \\
\hline
\end{tabular}

Table 1: Parameters the apps were evaluated on

We made a detailed description of each selected app. Table 1 shows the parameters that were described. The analysis was presented in one overall table for easy comparison. A one-row excerpt of this table is provided in figure 2.

For classifying the pedagogical design, we applied the framework of Goodwin and Highfield which they used to categorize educational applications [34, 35]. In line with their proposed categories, we considered whether the apps were instructive, manipulable, constructive, or a combination of these, i.e. instructive/manipulable or manipulable/constructive. Instructive apps are characterized as "game apps", using a combination of overt extrinsic rewards, providing clear goals and missions, and basing interaction on drill and practice. Manipulable apps provide opportunities for guided discovery, allowing for multiple responses and offering users various choices, whereas constructive apps are more like tools that are open-ended, incorporate limited extrinsic rewards and facilitate creativity. The framework is useful for distinguishing apps at a general level. 


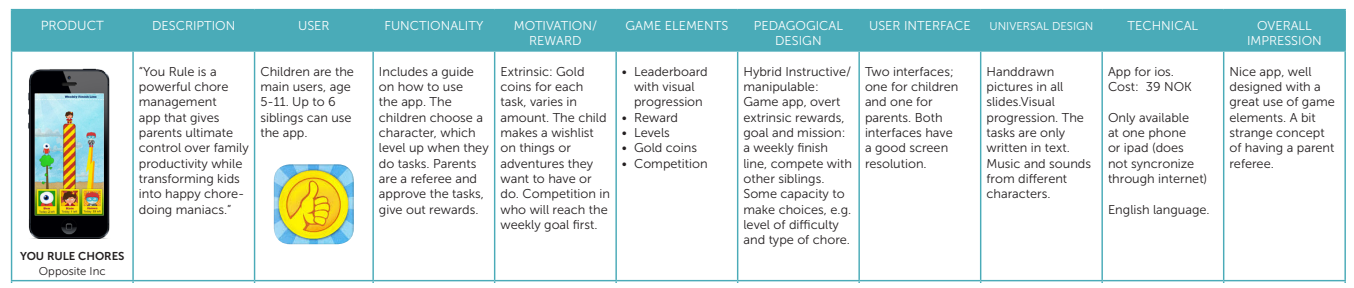

Figure 2: Excerpt from overall table

\section{$5 \quad$ Results}

In this section we present results from the app analysis. We have explored how gamification, i.e. introducing game design elements into non-game contexts, is incorporated in the 15 selected apps. We present the results by positioning the apps in 3 axes, and describe what features influenced the choice of position.

\subsection{Instructive, manipulable or constructive}

We found that most apps are characterized as instructive or hybrid instructive/manipulable, as shown in figure 3. The instructive apps contain overt extrinsic rewards and clear goals. The focus is on earning points and the task itself is reduced to a mere means to get to the important part - namely the rewards. The hybrids instructive/manipulable contain additional possibilities for guided discovery, some capacity to make choices and also multiple responses are possible.

Chore Monster is an example of an instructive app, where children tap "thumbs up" after having completed a task. This releases a certain amount of points (determined by parents). Moreover children get to spin a fortune wheel where it is possible to win different kinds of monsters; in addition children get access to short videos about monsters. Lickety Split is another app identified as an instructive app. This app incorporates time constraint as a game element, a so-called beat-the-clock game. As the hourglass gets filled, classical music is played and children can use it to endure a time period of 2 minutes for brushing teeth or to actually beat it when cleaning the room or putting on pajamas. Even though this app does not rely on the use of overt extrinsic reward, this app is characterized as instructive because of the clear mission and goal in addition to the focus on drill and practice.

You Rule is positioned as a hybrid between an instructive and manipulable app. The instructive element lies in that the game revolves around completing chores to earn coins, which unlocks avatar powers and can later be redeemed for rewards that children have wishlisted. The player who first finishes the weekly chores wins the game. The way of playing is through a competition intended to be among the children. As such, there is a clear focus on goals and missions. The manipulable aspect has to do with opportunities to choose levels of difficulties and kind of chores. The ways in which the characters will evolve through the new skills and powers can be understood as a kind of guided discovery. In Dreamhouse Tasks the tasks are related to different rooms and each room contains a number of stars, which symbolize different tasks. The tasks can be linked to a timer and when all the tasks have been 
carried out, the child can receive a reward (unspecified, to decide together with parents) and feed a pet character. This app is instructive in that the goals are clear and there is some use of extrinsic rewards, and manipulable in terms of guided discovery as well as some capacity to make choices.

Two apps are positioned as pure manipulable: Tejas and Lollipop `s great cleanup and Little Critter: Just helping my dad. These are interactive book apps, informing children about how to tackle messy rooms and the joy of helping out. Both apps include guided discovery by tapping things, looking for animations, learning words, finding mice and spiders, and more. One can choose to read out loud or listen to a narrative voice, as well as spend as much time as wanted on each page. This can be seen as a capacity to make choices.

None of the apps were characterized as constructive, thus apps that are open-ended, focus on creative input/interaction and facilitate intrinsic motivation rather than using overt extrinsic rewards. These findings correspond to the findings of Goodwin and Highfield in their study on educational apps $[34,35]$.

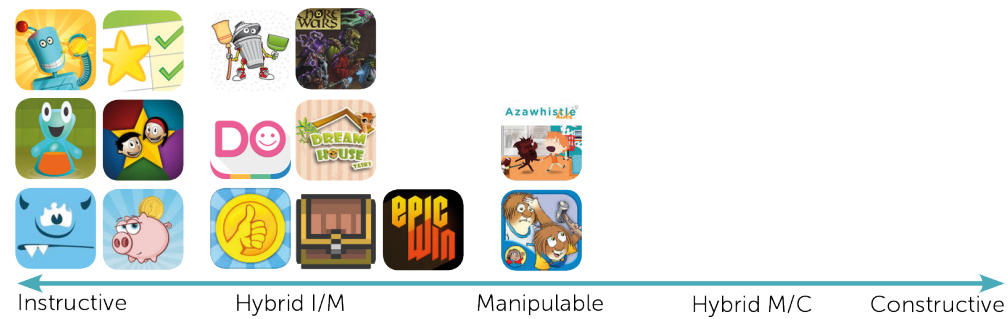

Figure 3: Apps positioned along axis of instructive, manipulable and constructive design

\subsection{Overt vs. limited use of extrinsic rewards:}

We found that many of the apps tend to focus on external (points, badges, highscore, etc.) rather than intrinsic motivation, as shown in figure 4. Funify Do is an app that uses extrinsic rewards. The children learn to earn ice cream, TV-time or other rewards, by performing tasks with assigned values. Parents need to check if the task has been done properly, before the children can get their reward. There is a clear goal, and feedback that mainly revolves around obtaining a specific reward. This is one way of showing children how parents get their income.

In the app Allowance \& Chores Bot, a robot character gives information and encouragement about the tasks. Here, the main focus is on extrinsic rewards in the form of allowance. iRewardChart is similar to a traditional chart and completed chores are rewarded with stars that can be subsequently redeemed for another reward. Both these apps emphasize the overt focus on extrinsic reward through the option called "punishment"; Parents can remove money and stars if a task is not carried out according to their expectations.

Dreamhouse Tasks is placed in the middle of the axis because it uses some extrinsic motivation by incorporating stars that eventually add up to fill a progress bar. Collected stars can be used to feed a pet animal and beyond this other rewards 
can not be specified in the app, leaving it more open for parents and children to decide about how they choose to make use of rewards.

Only a few apps limit the use of extrinsic rewards. Two of these apps are interactive stories, as mentioned in 5.1, and aimed for the youngest children. In Little Critter: Just Helping my Dad, the children meet the character Critter who spends the day helping his father with different chores. The story presents housework in the context of social values and family life, such as the importance of helping, togetherness, self-esteem and confidence. The game elements are connected to fantasy and curiosity as the player can find and collect hidden treasures. The way of playing is for children to explore the story alone or together with a parent. Most of the graphic elements are interactive in the sense that its verbal description is expressed when pressing it. Children can thus increase their vocabulary by learning words and their pronunciation when exploring the story. In Lickety Split, the player is rewarded with positive verbal feedback and children's rejoicing. The way of playing is to compete with time.

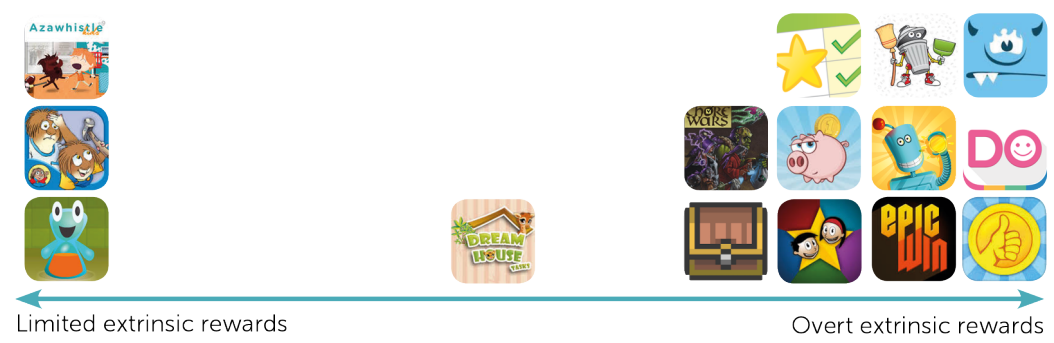

Figure 4: Apps positioned along axis of extrinsic rewards

\subsection{Individual vs. Family}

We found that most of the apps target family members individually, rather than focusing on the family as a whole.

Many of the apps have a twofold system, wherein children and parents have separate accounts. In this way, many of the apps give children and parents specific roles as respectively players and administrators. Even though it is quite possible for parents to participate as players on an equal footing as the children, many of the apps nevertheless provide a kind of frame that does not really encourage this. Parents are rather expected to take on a role as commander and controller, whereas children are offered the role as individual chore performers.

The idea of targeting the whole family is more present in the apps that offer storybased interaction. In Tejas and Lollipop's great cleanup for example, the underlying thought is to encourage understanding about how tidying up can be a meaningful activity and make you feel at ease in your surroundings.

The focus on individual performance as opposed to a family performance can be seen in relation to the use of specific game elements, namely competition and collaboration. The apps that target individual players also tend to use competition as approach, as shown in figure 5. The two apps placed in the middle take a more teambased approach wherein competition is somehow based on social encouragement. 


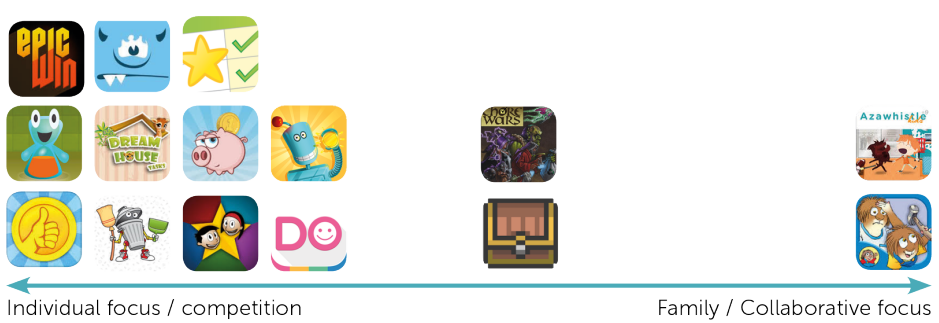

Figure 5: Apps positioned along axis of individual focus/competition and family/collaborative focus

To sum up the results from analyzing a selection of apps that gamify chores we draw attention to the following points:

- Most apps are characterized as instructive or hybrid instructive/manipulable and there is a lack of constructive apps

- Most apps use overt extrinsic rewards

- Most apps target family members individually, rather than the family as a whole

\section{Discussion}

In this section we discuss the results from a motivation perspective by asking: How can the chore apps facilitate intrinsic motivation? We focus on the three principles from SDT: Competence, autonomy and relatedness.

Referring to the pedagogical design of the selected apps, the most commonly used approach is characterized as instructive or as hybrid instructive/manipulable. There is a lack of constructive apps. In a way, this can be compared with only offering readymade worksheets for coloring (instructive) as opposed to blank paper sheets. The different kinds of sheets can serve different purposes. The same can be true for apps and in our case for chore apps. The instructive apps, thus the apps combining overt extrinsic rewards, clear goals and missions as well as a so-called drill and practice method, can have different benefits for achieving intrinsic motivation in terms of competence. Facilitation of competence has to do with the feeling of mastering a system. Apps that provide clear instructions, offering a frame with explicit goals and tangible outcomes, can contribute to experiencing a task as fun and meaningful. However, this is not necessarily related to actually conducting the chore itself, rather conducting the chore may become a means to obtain something that is perceived as fun and meaningful.

By working towards an overt extrinsic reward, one can acquire specific skills and confidence in own capabilities (self-efficacy). For example, through regular repetition of making the bed or taking out the garbage one gets gradually better at it and also aware that it does not happen by itself. There is also a chance that extrinsic rewards contribute to reduce a task to something standing in the way and therefore will be halfheartedly performed. In this case, competence and intrinsic motivation will not be facilitated. A constructive approach, one offering a less rigid system, can provide 
opportunities for making own games. Referring to the drawing sheet metaphor provided with blank paper sheets and some pencils, new drawings can be made each time and there is always something new to discover.

Most apps target family members individually. As shown in figure 5, individual participation is often related to competition as a game design element. An individualcompetitive approach can make a game engaging and meaningful. On the other hand, this approach might also weaken one's sense of autonomy. Autonomy has to do with the freedom of choosing to participate or not. A chore system that is all about competition between siblings might be suitable for some siblings while being perceived as unfair by other siblings. Moreover, predefining a marked distinction between the roles that parents and children are expected to have, such as assigning parents the roles as the referee (distributing, defining and approving tasks) while children are represented by cartoon-like avatars (conducting tasks as efficient as possible in competition with siblings), can either reflect or indeed contravene the actual roles and how they are experienced within families. Such representations can influence the game play in different ways and affect autonomy. Gamification of chores can, however, also lead to a strengthening of autonomy. If the game is adapted to all the players in such a way that there is a balance between their skills and the offered challenges, they can experience flow and as such find participation meaningful. A pedagogical design that allows for some manipulation or construction should support autonomy.

Relatedness has to do with meaningful interaction with other people. Depending on game design elements, apps can facilitate for relatedness to varying degrees. A certain view on players as well as task is conveyed through use of game design elements and specific language. For instance, the idea to combine competition with the concepts of reward and punishment is different from the idea to combine collaboration with the concepts of inspiration and happiness. Encouraging direct collaboration within the family, as a way of playing, is an approach that can foster positive social interaction, self-worth and intrinsic motivation.

To end our discussion, we present some suggestions that can serve as inspiration for app or digital designers seeking to motivate the whole family to enjoy household chores through gamification:

- Explore how hybrid manipulable/constructive or constructive pedagogical designs can foster positive and fun ways of doing chores. Let the family be a team of "explorers" and inspire them to come up with new and better ways to solve tasks, or simply to come up with new tasks that can be done. As mentioned, blank sheets can foster creativity.

- Limit the extrinsic rewards, and focus on tasks that can provide autonomy, relatedness and competence. One way of doing this is to make the actual housework more of a game, than a checklist, like in Huizinga's magical circle [32]. Let the children pick the tasks that they want to do - this can increase their autonomy and competence. Support the right conditions: create a positive/fun/engaging/meaningful frame to foster play.

- Focus on collaboration and the whole family, rather than on the individual. Add mechanisms that encourage parents and children to do things together. Inspire families to talk about and decide upon a set of family values. 
Competition can be used, but a suggestion is to have a common goal rather than an individual one.

\section{$7 \quad$ Conclusion and further research}

In this paper we explored how gamification is incorporated in 15 apps that aim to motivate people, and notably children, to contribute with family housework. First of all, we found that most of the apps are characterized as instructive or hybrid instructive/manipulable and there is a lack of constructive apps. This means that the apps do not facilitate open-ended exploration and user's own creative input. Second, we found that the apps use overt extrinsic rewards, rather than appeal to intrinsic rewards. This means that there is limited focus on the actual housework and less opportunity to gamify the activities as such. Third, we found that the apps target family members individually, rather than the family as a whole. This means that values concerning collaboration are not fully employed as drivers for intrinsic motivation.

We have come up with a list of suggestions for future chore app development. This includes focusing on autonomy, competence and relatedness, to use limited extrinsic rewards, to focus on collaboration rather than the individual, and to explore the constructive and more open field of play. The next step for future research and development is to move away from a theoretical analysis of the apps. Instead we want to study the apps in real use and involve families in a user-centered design process in order to further develop the potential that gamification might have as approach to facilitate intrinsic motivation among all family members.

\section{$8 \quad$ References}

1. Deterding, S., et al., From game design elements to gamefulness: defining "gamification". In Pro. MindTrek'11, 2011. ACM Press, p. 9-15.

2. Hook, J.L., Gender Inequality in the Welfare State: Sex Segregation in Housework, 1965-2003. American Journal of Sociology, 2010. 115(5): p. 1480-1523.

3. Bernhardt, E., T. Noack, and T.H. Lyngstad, Shared housework in Norway and Sweden: advancing the gender revolution. Journal of European Social Policy, 2008. 18(3): p. 275-288

4. Solberg, A., Negotiating childhood: Changing constructions of age for Norwegian children. In A. James and A. Prout (Eds.) Constructing and Reconstructing Childhood: Contemporary Issues in the Sociological Study of Childhood. 1997, London: Falmer Press. p. 126-144.

5. Miller, P. and J. Bowd, Family time economies and democratic division of work. Journal of Family Studies, 2014. 20(2): p. 128-147.

6. Cunningham, M., Parental Influences on the Gendered Division of Housework. American Sociological Review, 2001. 66(2): p. 184-203.

7. Bjering, A.B., Design of a digital application to motivate families to do domestic chores together (Master thesis), Department of Product Design. Norwegian University of Science and Technology, 2015.

8. Bringsværd, T.A. and T. Soli, Når to skal rydde. 2006, Oslo: Gyldendal.

9. Wolde, G. and E. Birke, Emma støvsuger. 2002, Oslo: Aschehoug.

10. Deci, E.L. and R.M. Ryan, Intrinsic motivation and self-determination in human 
Behavior. 1985. Springer Science \& Business Media.

11. Werbach, K. and D. Hunter, For the win: how game thinking can revolutionize your business. 2012, Philadelphia: Wharton Digital Press.

12. Skinner, B.F., The behavior of organisms: an experimental analysis. 1938, Oxford, England: Appleton-Century.

13. Bandura, A., Social cognitive theory of self-regulation. Organizational Behavior and Human Decision Processes, 1991. 50(2): p. 248-287.

14. Ryan, R.M. and E.L. Deci, Self-determination theory and the facilitation of intrinsic motivation, social development, and well-being. American psychologist, 2000. 55(1): p. 68-78.

15. Ryan, R.M. and E.L. Deci, Intrinsic and Extrinsic Motivations: Classic Definitions and New Directions. Contemporary Educational Psychology, 2000. 25(1): p. 54-67.

16. Csikszentmihalyi, M., Flow: The psychology of optimal experience. 1990, New York: Harper \& Row.

17. McGrath, J. and B. Bates, The little book of big management theories ... and how to use them. 2013, Harlow, England: Pearson.

18. Hackman, J.R. and G.R. Oldham, Motivation through the design of work: test of a theory. Organizational Behavior and Human Performance, 1976. 16(2): p. 250-279.

19. Herzberg, F.I., Work and the nature of man. 1966, Cleveland, Ohio: World Pub. Co.

20. Skaalvik, E.M. and S. Skaalvik, Skolens laringsmilj $\phi$ : selvopfattelse, motivasjon og laeringsstrategier. 2007, København: Akademisk Forlag.

21. Bandura, A., Self-efficacy: Toward a unifying theory of behavioral change. Psychological Review. 1977. 84(2): p. 191-215.

22. Covington, M.V., The Self-Worth Theory of Achievement Motivation: Findings and Implications. The Elementary School Journal, 1984. 85(1): p. 5-20.

23. Holloway, D., L. Green, and S. Livingstone, Zero to eight. Young children and their internet use. 2013, London: EU Kids Online.

24. Zichermann, G. and C. Cunningham, Gamification by Design: implementing game mechanics in web and mobile apps. 2011, Sabastobol: O'Reilly Media.

25. Xu, F., J. Weber, and D. Buhalis, Gamification in Tourism. In Z. Xiang and I. Tussyadiah, (Eds.), Information and Communication Technologies in Tourism 2014. 2013, Springer, p. 525-537.

26. Juul, J., The game, the player, the world: Looking for a heart of gameness. PLURAISRevista Multidisciplinar da UNEB, 2010. 1(2).

27. Salen, K. and E. Zimmerman, Rules of play: game design fundamentals. 2004, Cambridge: MIT Press.

28. McGonigal, J., Reality is broken: why games make us better and how they can change the world. 2012, London: Vintage books.

29. Reeves, B. and J.L. Read, Total engagement: using games and virtual worlds to change the way people work and businesses compete. 2009, Boston: Harvard Business Press.

30. Schell, J. The Pleasure Revolution: Why games Will Lead the Way. [Video] November 2011; Available from: https://http://www $. y o u t u b e . c o m / w a t c h ? v=4 P k U g C i H u H 8 \&$ feature=youtu.$b e$.

31. Reimer, C., Play to order: what Huizinga has to say about gamification. In Pro. Games + Learning + Society Conference. 2011, ETC Press, p. 272-274.

32. Huizinga, J., Homo ludens: a study of the play-element in culture. 1955, Boston: Beacon Press.

33. Robertson, M. Can't play, won't play. 2010, October [cited 2015 05.05.]; Available from: http://hideandseek.net/2010/10/06/cant-play-wont-play/.

34. Goodwin, K. and K. Highfield. iTouch and iLearn: an examination of "educational" Apps. In Early education and technology for children conference. 2012.

35. Goodwin, K. and K. Highfield, A framework for examining technologies and early mathematics learning. In Reconceptualizing Early Mathematics Learning. 2013, Springer. p. 205-226. 